Special Issue: Osteoimmunology and vascular biology Mini Review

\title{
Osteoimmunology: the effect of inflammation on bone
}

\author{
Tomoki Nakashima ${ }^{1,2,3)}$ and Hiroshi Takayanagi ${ }^{1,2,3, *)}$ \\ ${ }^{1)}$ Department of Cell Signaling, Graduate School of Medical and Dental Sciences, Tokyo Medical and Dental \\ University, Tokyo, Japan \\ 2)Japan Science and Technology Agency (JST), Explorative Research for Advanced Technology (ERATO) \\ Program, Takayanagi Osteonetwork Project, Tokyo, Japan \\ ${ }^{3)}$ Global Center of Excellence (GCOE) Program, International Research Center for Molecular Science in Tooth \\ and Bone Diseases, Tokyo, Japan
}

The bony skeleton enables locomotive activity, the storage of calcium, and the harboring of the hematopoietic stem cells from which blood and immune cells are derived. Although bone appears to be metabolically inert, it is actually a dynamic organ, under the active control of osteoblasts and osteoclasts. Excessive activity of osteoclasts leads to pathological bone resorption, as seen in a variety of local or generalized osteopenic conditions. Therefore, the elucidation of the regulatory mechanisms involved in osteoclastogenesis is critical for the understanding of the skeletal system in both health and disease. The immune and skeletal systems share various molecules, including cytokines, signaling molecules, transcription factors and membrane receptors. Investigation of rheumatoid arthritis (RA), as well as the cloning of RANKL and identification of the various bone phenotypes found in immune-compromised genetically modified mice, have highlighted the importance of the dynamic interplay between the two systems. RANKL stimulates osteoclastogenesis through nuclear factor of activated T cells (NFAT) c1, which is also a crucial regulator of immunity. In RA, bone destruction is caused by the enhanced activity of osteoclasts, which is mainly dependent on interleukin-17-producing helper $T$ cells ( $\left.T_{H} 17\right)$. These findings led to the emergence and subsequent rapid evolution of the field of osteoimmunology. The scope of osteoimmunology has been extended to encompass a wide range of molecular and cellular interactions, and its framework will provide a scientific basis for future therapeutic approaches to diseases related to both of these systems.

Rec./Acc.10/6/2011, pp404-412

\footnotetext{
* Correspondence should be addressed to:

Hiroshi Takayanagi, MD, PhD, Department of Cell Signaling, Graduate School of Medical and Dental Sciences, Tokyo Medical and Dental University, Yushima 1-5-45, Bunkyo-ku, Tokyo 113-8549, Japan. Phone: +81-3-5803-5471, Fax: +813-5803-0192, E-mail: taka.csi@tmd.ac.jp
} 


\section{Introduction}

The endocrine system has traditionally been understood to be mainstay regulatory system of the osteoclast lineage; however, accumulating evidence has made it clear that osteoclasts and immune cells share a number of regulatory molecules, including cytokines, receptors, signaling molecules and transcription factors that mutually influence each other. Furthermore, immune cells are derived from bone marrow, and thus develop in the same microenvironment as osteoclasts ${ }^{1,2)}$. In fact, patients with excessive activation of the immune system, as in the case of arthritis, are also at higher risk of experiencing concomitant osteoporosis as well as localized bone destruction. In addition, mice deficient in immunomodulatory molecules have been found to frequently develop an abnormal osteoclast phenotype ${ }^{1)}$, and these animals have provided important insight into osteoclast biology. Here, we summarize recent progress in the understanding of osteoclast development in the context of the newly established interdisciplinary field of “osteoimmunology" ${ }^{1,2}$.

\section{The crucial role of RANKL in bone metabo- lism}

A relationship between the immune and skeletal systems has long been recognized. Almost four decades ago, antigen-stimulated immune cells were shown to produce soluble factors that stimulate osteoclastic bone resorption ${ }^{1)}$. In the 1980s, interleukin (IL)-1 was identified to be one of these factors ${ }^{1)}$. An in vitro coculture system for osteoclast formation was first established in the late 1980's. This system revealed the importance of the cell-to-cell contact that takes place between osteoblasts/stromal cells and hematopoietic cells for osteoclast differentiation ${ }^{3)}$. Based on this, it was proposed that osteoclastogenesis-supporting mesenchymal cells express the osteoclast differentiation factor (ODF) as a membrane-associated protein ${ }^{4}$.

In 1997, a potential inhibitor of osteoclastogenesis, osteoprotegerin (OPG), was cloned ${ }^{1,4)}$. In 1998, OPG was identified as a decoy receptor that associates with a transmembrane protein of the TNF superfamily, OPGL, the long-sought $\mathrm{ODF}^{1,4)}$. Interestingly, immunologists cloned the same molecule as a stimulator of dendritic cells expressed by $\mathrm{T}$ cells, and called it receptor activator nuclear factor- $\kappa \mathrm{B}$ ligand (RANKL) or TNFrelated activation-induced cytokine (TRANCE) ${ }^{1,4)}$. The receptor for RANKL is RANK, a type I transmembrane protein, which assembles into a functional trimer, similar to other members of the TNF receptor family ${ }^{1,4)}$. Mice with a disruption of Rank or Rankl exhibit severe osteopetrosis accompanied by a defect in tooth eruption caused by a complete absence of osteoclasts. These genetic findings clearly demonstrated that RANK and RANKL are essential for osteoclastogenesis in $v i v{ }^{1,5)}$. By contrast, mice lacking OPG exhibit severe osteoporosis resulting from both an increased number and enhanced activity of osteoclasts ${ }^{5)}$. In humans, mutations in RANK, RANKL and OPG have been identified in patients with bone disorders such as familial expansile osteolysis, autosomal recessive osteopetrosis and Juvenile Paget's disease, respectively ${ }^{5}$.

\section{The expression and regulation of RANKL in bone}

RANKL functions as a membrane-anchored molecule which is released from the cell surface as a soluble molecule following proteolytic cleavage by matrix metalloproteinases (MMPs) such as MMP-14,7). Both soluble and membrane-bound RANKL function as agonistic ligands for RANK. However, we and others have suggested that membrane-bound RANKL functions more efficiently than soluble RANKL ${ }^{6,8,9)}$. In addition, previous studies have indicated that RANKL serves as both a chemotactic and survival factor for osteoclasts ${ }^{10,11)}$. RANKL is extensively expressed in mesenchymal cells such as osteoblast/stromal and synovial cells. RANKL expression on calvarial cells, including osteoblasts, is upregulated by certain osteoclastogenic factors such as vitamin $\mathrm{D}_{3}$, prostaglandin $\mathrm{E}_{2}$, parathyroid hormone, IL-1, IL-6, IL-11, IL-17 and TNF- $\alpha^{6,12)}$. However, the major source of RANKL in vivo remains unclear, since RANKL is expressed by several different cell types in both bone and bone marrow, including osteoblasts, osteocytes, stromal cells and lymphocytes. Recently, we demonstrated that osteocytes embedded within the bone matrix express a much higher amount of RANKL and have a much greater capacity to support osteoclastogenesis than either osteoblasts or stromal cells. Furthermore, the crucial role of RANKL that is expressed by osteocytes was confirmed by the severe osteopetrotic phenotype observed in mice specifically lacking RANKL in osteocytes. These results clearly indicate that the osteocytes are the major source of RANKL in the bone remodeling in vivo ${ }^{13)}$.

\section{Regulation of RANKL signaling}

RANK is a transmembrane molecule expressed on osteoclast progenitor cells and mature osteoclasts. Ligation of RANK with RANKL results in the commitment of monocyte/macrophage precursor cells to the osteoclast lineage and the activation of mature osteoclasts. RANK lacks intrinsic enzymatic activity in its intracellular domain, and transduces signals by recruiting adaptor molecules such as the TNF receptor-associated factor 
(TRAF) family of proteins ${ }^{1}$. Genetic approaches followed by intensive molecular analyses have identified TRAF6 as the main adaptor molecule that links RANK to the differentiation and function of osteoclasts (Fig.1) ${ }^{14-16)}$. By an as yet unknown mechanism, RANKL binding to RANK induces the trimerization of RANK and TRAF6, which leads to the activation of nuclear factor- $\kappa \mathrm{B}$ $(\mathrm{NF}-\kappa \mathrm{B})$ and mitogen-activated kinases (MAPKs) ${ }^{17)}$. It has not yet determined how RANK alone, among the TRAF6-binding receptors, is able to stimulate osteoclastogenesis so potently. Additional RANK-specific adaptor molecules might exist to link RANK signaling to other pathways ${ }^{18}$. For example, the molecular scaffold Grb2-associated binding protein 2 (Gab2) and four and a half LIM domain 2 (FHL2) have been shown to be associated with RANK and to have an important role in its signal transduction ${ }^{19,20)}$. The tyrosine kinases Btk and Tec have been shown to be activated by RANK and to enhance the calcium signaling ${ }^{21)}$ (see below).

The essential role of $\mathrm{NF}-\kappa \mathrm{B}$ in osteoclastogenesis has been demonstrated genetically ${ }^{22,23)}$. NF- $\kappa$ B p50 and p52 double-deficient mice develop severe osteopetrosis because of a defect in osteoclastogenesis. The activator protein 1 (AP-1) transcription factor complex is also essential for osteoclastogenesis ${ }^{24)}$. RANK activates AP-1 through the induction of the component c-Fos, which has recently been shown to be dependent on the activation of calcium/calmodulin-dependent protein kinase type IV (CaMKIV) and cyclic AMP-responsive element-binding protein $(\mathrm{CREB})^{25)}$.

\section{The osteoclastogenic transcription factor NFATc1}

Importantly, RANKL specifically and potently induces nuclear factor of activated T cells, cytoplasmic 1 (NFATc1), the master regulator of osteoclast differentiation, and this induction is dependent on both the TRAF6-NF- $\kappa$ B and the c-Fos pathways $(\text { Fig.1 })^{26)}$. The NFAT family of transcription factors was originally discovered in $\mathrm{T}$ cells, but they are involved in the regulation of various biological systems ${ }^{27,28)}$. Activation of NFAT is mediated by a specific phosphatase, calcineurin, which is activated by calcium-calmodulin signaling. The essential and sufficient role of the Nfatc1 gene in osteoclastogenesis has been shown both in vitro and in vivo ${ }^{26,29)}$. The Nfatc1 promoter contains NFAT binding sites and NFATc1 specifically autoregulates its own promoter during osteoclastogenesis, thus enabling the robust induction of NFATc $1^{29)}$. AP-1 containing c-Fos, together with continuous activation of calcium signaling, is crucial for this autoamplification $^{26,30)}$. NFATc1 regulates a number of osteoclast- specific genes in cooperation with other transcription factors such as AP-1, PU.1 and MITF ${ }^{1}$. On the other hand, NFATc1 activity is negatively regulated by other transcription factors, such as interferon regulatory factor-8 (IRF-8), B cell lymphoma 6 (Bcl6) and the v-maf musculoaponeurotic fibrosarcoma oncogene family member protein $\mathrm{B}$ (MafB), during osteoclastogenesis ${ }^{31-33)}$. The expression of such negative regulators was observed to be repressed through osteoclastogenesis. This repression is consistent with the notion that high NFATc1 activity is a prerequisite for efficient osteoclastogenesis, but the mechanism by which the expression of these anti-osteoclastogenic regulators is repressed during RANKL-induced osteoclastogenesis has remained obscure. Recent data from our and other laboratories indicate that B lymphocyte-induced maturation protein-1 (Blimp1), which is induced by RANKL through NFATc1 during osteoclastogenesis, functions as a transcriptional repressor of anti-osteoclastogenic genes such as Irf8, Bcl6 and Mafb ${ }^{32,34)}$. Therefore, NFATc1 choreographs the determination of cell fate in the osteoclast lineage by inducing the repression of negative regulators as well as through its effect on positive regulators (Fig.1).

\section{Calcium signaling and immunoreceptors in osteoclastogenesis}

Phospholipase $\mathrm{C} \gamma$ ( $\mathrm{PLC} \gamma$ ), which mediates $\mathrm{Ca}^{2+}$ release from intracellular stores, is crucial for the activation of the key transcription factor NFATc1 via calcineurin (Fig.1 ${ }^{26)}$. However, despite the evident importance of the calcium-NFAT pathway, it had long been unclear how RANKL activates calcium signals. RANK belongs to the TNF receptor family, which has yet to be directly connected to calcium signaling. The activation of PLC $\gamma$ by RANK requires the protein tyrosine kinase Syk, along with immunoreceptor tyrosine-based activation motif (ITAM)-bearing molecules, such as DNAX-activating protein (DAP12) and the $\mathrm{Fc}$ receptor common gamma chain $(\mathrm{FcR} \gamma)^{35)}$. As ITAM signals are essential for osteoclastogenesis, but by themselves cannot induce osteoclastogenesis, these signals should properly be considered costimulatory signals for RANK. Thus, the ITAM signal is critical for calcium signaling in the osteoclast lineage as well as in lymphocytes.

It is also conceivable that RANK activates an as yet unknown pathway that specifically synergizes with or upregulates ITAM signaling. Recently, we have shown that the Tec family tyrosine kinases such as Btk and Tec are activated by RANK and are involved in the phosphorylation of PLC $\gamma(\text { Fig.1 })^{21)}$. An osteopetrotic phenotype in Tec and Btk double-deficient mice revealed these two kinases play an essential role in the regulation of 


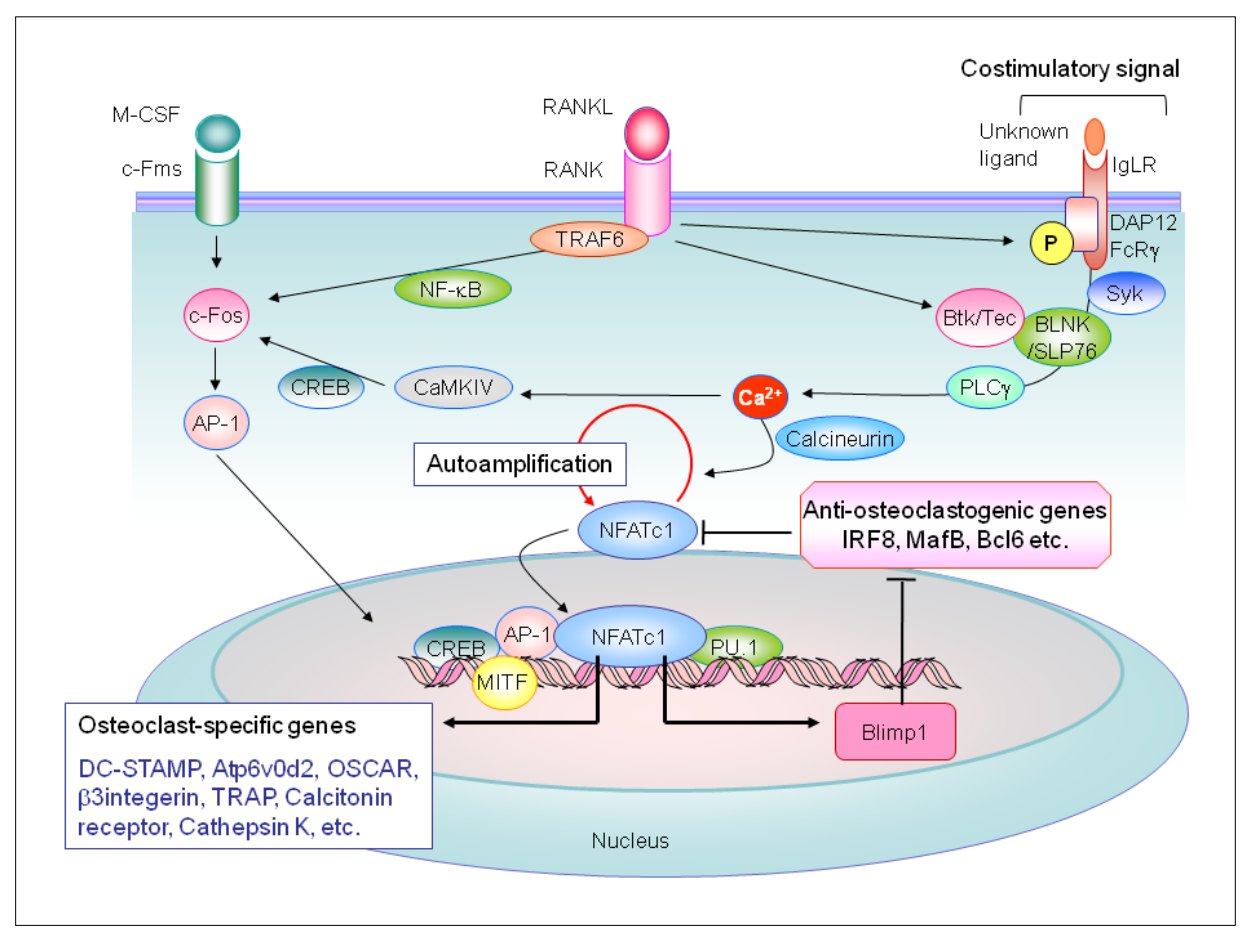

Fig.1 Signal transduction in osteoclast differentiation

RANKL binding to its receptor RANK results in the recruitment of TRAF6, which activates NF- $\kappa$ B and JNK-c-Jun. RANKL also stimulates the induction of a component of AP-1, c-Fos, which is dependent on NF- $\kappa$ B and CREB. AP-1 contributes to the more robust induction of NFATc1, which is based on an autoamplifying mechanism that is effected through persistent calcium signal-mediated activation of NFATc1 (NFATc1 binds to NFAT-binding sites on its own promoter, constituting a positive feedback loop). Immunoglobulin-like receptors (IgLR; OSCAR, PIR-A, TREM-2 and SIRP $\beta 1$ ) associate with FcR $\gamma$ and DAP12, both of which contain ITAM. ITAM signaling functions as a costimulatory signal for RANK, which is essential for Syk activation, phosphorylation of PLC $\gamma$ and subsequent activation of calcium signaling. The tyrosine kinases Btk and Tec, activated by RANK, also promote phosphorylation of PLC $\gamma$, thus linking the RANK and ITAM pathways. In the nucleus, NFATc1 cooperates with other transcription factors such as AP-1, PU.1, CREB and MITF to induce various osteoclastspecific genes. On the other hand, NFATc1 activity is negatively regulated by other transcription factors such as IRF-8, Bcl6 and MafB during osteoclastogenesis. Blimp1 is induced by RANKL through NFATc1, and functions as a transcriptional repressor of antiosteoclastogenic genes. Thus, NFATc1 choreographs the determination of cell fate in the osteoclast lineage by inducing the repression of negative regulators as well as through its effect on positive regulators. RANKL, receptor activator of nuclear factor- $\kappa$ B ligand; TRAF6, tumor necrosis factor receptor-associated factor 6 ; NF- $\kappa \mathrm{B}$, nuclear factor- $\kappa \mathrm{B}$; JNK, JUN N-terminal kinase; NFATc1, nuclear factor of activated T cells cytoplasmic 1; AP-1, activator protein 1; CREB, CAMP-responsive element-binding protein; OSCAR, osteoclast-associated receptor; PIR-A, paired immunoglobulin-like receptor $A$; TREM-2, triggering receptor expressed in myeloid cells 2; SIRP $\beta 1$, signal-regulatory protein $\beta 1 ; \mathrm{FcR} \gamma$, Fc receptor common $\gamma$ subunit; DAP12, DNAX-activating protein; ITAM, immunoreceptor tyrosine-based activation motif; Syk, spleen tyrosine kinase; PLC $\gamma$, phospholipase $\mathrm{C} \gamma$; Btk, Brutonבs tyrosine kinase; MITF, microphthalmia-associated transcription factor; PIR-B, paired immunoglobulin-like receptor B; SHP1, $\mathrm{SH} 2$-domain-containing protein tyrosine phosphatase 1; IRF-8, IFN regulatory factor-8; Bcl6, B cell lymphoma 6; MafB, v-maf musculoaponeurotic fibrosarcoma oncogene family, protein B; Blimp1, B lymphocyte-induced maturation protein-1. 
osteoclastogenesis. Tec and Btk had been reported to play a key role in proximal BCR signaling, but this study established their crucial role in linking RANK and ITAM signaling.

\section{The crucial role of osteoclasts in bone loss in arthritis}

Activation of the immune system is essential for host defense against pathogens, but aberrant and/or prolonged activation under pathological conditions results in tissue damage owing to the activation of effector cells. In rheumatoid arthritis (RA), it has long been a challenging question how abnormal T-cell activation (characterized by infiltration of $\mathrm{CD} 4^{+} \mathrm{T}$ cells) mechanistically induces bone damage ${ }^{1)}$. In the early 1980 s, researchers observed osteoclast-like cells at the bone destruction sites ${ }^{36}$. This finding led to the hypothesis that osteoclasts have an important role in bone destruction in arthritic joints and that these cells are formed in the synovium ${ }^{37,38)}$. We demonstrated efficient osteoclastogenesis in primary synovial cell cultures obtained from RA patients ${ }^{37)}$. Moreover, high RANKL expression has been detected specifically in the synovium of RA patients ${ }^{39,40)}$. Additionally, osteoclast-deficient mice are protected from bone erosion in arthritis models $\mathrm{s}^{41,42)}$. In the absence of osteoclasts, bone destruction did not occur despite a similar level of inflammation, indicating that both RANKL and osteoclasts are indispensable for the bone loss caused by inflammation. Blocking RANKL by OPG treatment significantly prevented bone destruction in adjuvant arthritis ${ }^{43)}$. Consistent with this, anti-RANKL and anti-osteoclast therapies have been shown to be beneficial in the treatment of RA in human trials ${ }^{43-45)}$.

\section{Regulation of osteoclastogenesis by $\mathrm{T}$ cells}

As RANKL is expressed in activated T cells, T cells might directly induce osteoclast differentiation by acting on osteoclast precursor cells under pathological conditions ${ }^{43}{ }^{46}$. However, the interferon- $\gamma(\mathrm{IFN}-\gamma)$ produced by $\mathrm{T}$ cells potently suppresses RANKL signaling through rapid degradation of TRAF ${ }^{47)}$. To fully understand the effects of T cells on osteoclastogenesis, it is absolutely necessary to elucidate the specific effects of the various cytokines which $\mathrm{T}$ cells produce. The effects of $\mathrm{T}$ cells on osteoclastogenesis would be expected to be dependent on the balance between positive and negative factors expressed by the $\mathrm{T}$ cells. As the $\mathrm{CD}_{4}{ }^{+} \mathrm{T}$ helper $\left(\mathrm{T}_{\mathrm{H}}\right)$-cell subsets $\mathrm{T}_{\mathrm{H}} 1$ and $\mathrm{T}_{\mathrm{H}} 2$ produce IFN- $\gamma$ and IL-4, respectively, both of which are antiosteoclastogenic, it has been a paradox how the activated $\mathrm{CD} 4^{+} \mathrm{T}$ cells in arthritis enhances osteoclastogenesis in the presence of these cytokines (Fig.2). In this context it is worthwhile to define what we believe to be a very rare but pathologically important $\mathrm{T}_{\mathrm{H}}$-cell subset responsible for abnormal bone resorption, as osteoclastogenic $\mathrm{T}_{\mathrm{H}}$ cells $\left(\mathrm{T}_{\mathrm{HOc}}\right.$ cells) ${ }^{1)}$. Previous investigations from our laboratory and others on synovial $\mathrm{T}$ cells in rheumatoid arthritis have determined the characteristics of $\mathrm{THOc}_{\mathrm{H}}$ cells. First, $\mathrm{T}_{\mathrm{HOc}}$ cells do not produce a large amount of IFN- $\gamma$. Second, they trigger local inflammation and the production of inflammatory cytokines, including TNF- $\alpha$, which induce RANKL expression on synovial fibroblasts. Third, THOc cells express RANKL and thus might directly participate in accelerated osteoclastogenesis (Fig.2). As these TH cells have just such osteoclastogenic characteristics, they can tip the balance in favor of osteoclastogenesis in a number of ways. Although autoimmune arthritis has been traditionally classified as a TH1-type disease, $\mathrm{T}_{\mathrm{H}} 1$ cells do not have the entire repertoire of the requisite characteristics, indicating that these $\mathrm{THO}_{\mathrm{H}} \mathrm{Oc}$ cells might belong to an as yet unknown subset.

\section{TH17 cells function exclusively as an osteo- clastogenic T cell subset}

Data from our laboratory indicate that an IL-17 producing $\mathrm{TH}_{\mathrm{H}}$ cell subset $\left(\mathrm{T}_{\mathrm{H}} 17\right.$ cells) represents the long-sought-after $\mathrm{T}_{\mathrm{HOc}}$ cell subset among the known $\mathrm{CD}^{+}{ }^{+} \mathrm{T}$ cell lineages, whereas $\mathrm{T}_{\mathrm{H}} 1$ and $\mathrm{T}_{\mathrm{H}} 2$ cells have anti-osteoclastogenic effects (Fig.2) ${ }^{48)}$. It has already been reported that IL-17 expression is increased in RA joints ${ }^{49)}$. It is well established that IL-17 induces local inflammation in autoimmune diseases through inflammatory cytokine production $^{50-52)}$. Moreover, IL-17 induces RANKL on mesenchymal cells ${ }^{49)}$. We have also shown that $\mathrm{T}_{\mathrm{H}} 17$ cells express higher levels of RANKL than either $\mathrm{T}_{\mathrm{H}} 1$ or $\mathrm{T}_{\mathrm{H}} 2$ cells $^{48}$. Therefore, the infiltration of $\mathrm{T}_{\mathrm{H}} 17$ cells into the inflammatory lesion links the abnormal T-cell response to bone damage in arthritis, and the pathogenesis of RA should be reconsidered as a TH17-type disease (Fig.2). Clearly, this subset is an auspicious target for future therapies, and cytokines related to $\mathrm{T}_{\mathrm{H}} 17$-cell differentiation and expansion, such as IL-6, TGF- $\beta$ and IL-23, are of great potential clinical importance ${ }^{53,54}$. A recent study has reported that the nuclear $\mathrm{I} \kappa \mathrm{B}$ family member $\mathrm{I} \kappa \mathrm{B} \zeta$ was most highly expressed in TH17 cells among the helper T cell subsets and IL-17 production in $\mathrm{I} \kappa \mathrm{B} \zeta$-deficient $\mathrm{T}$ cells was markedly reduced. Notably, $\mathrm{I} \kappa \mathrm{B} \zeta$-deficient mice were shown to be highly resistant to experimental autoimmune encephalomyelitis ${ }^{55)}$. These findings indicate that $\mathrm{I} \kappa \mathrm{B} \zeta$ is critical for the transcriptional program in $\mathrm{T}_{\mathrm{H}} 17$ cell lineage commitment. 


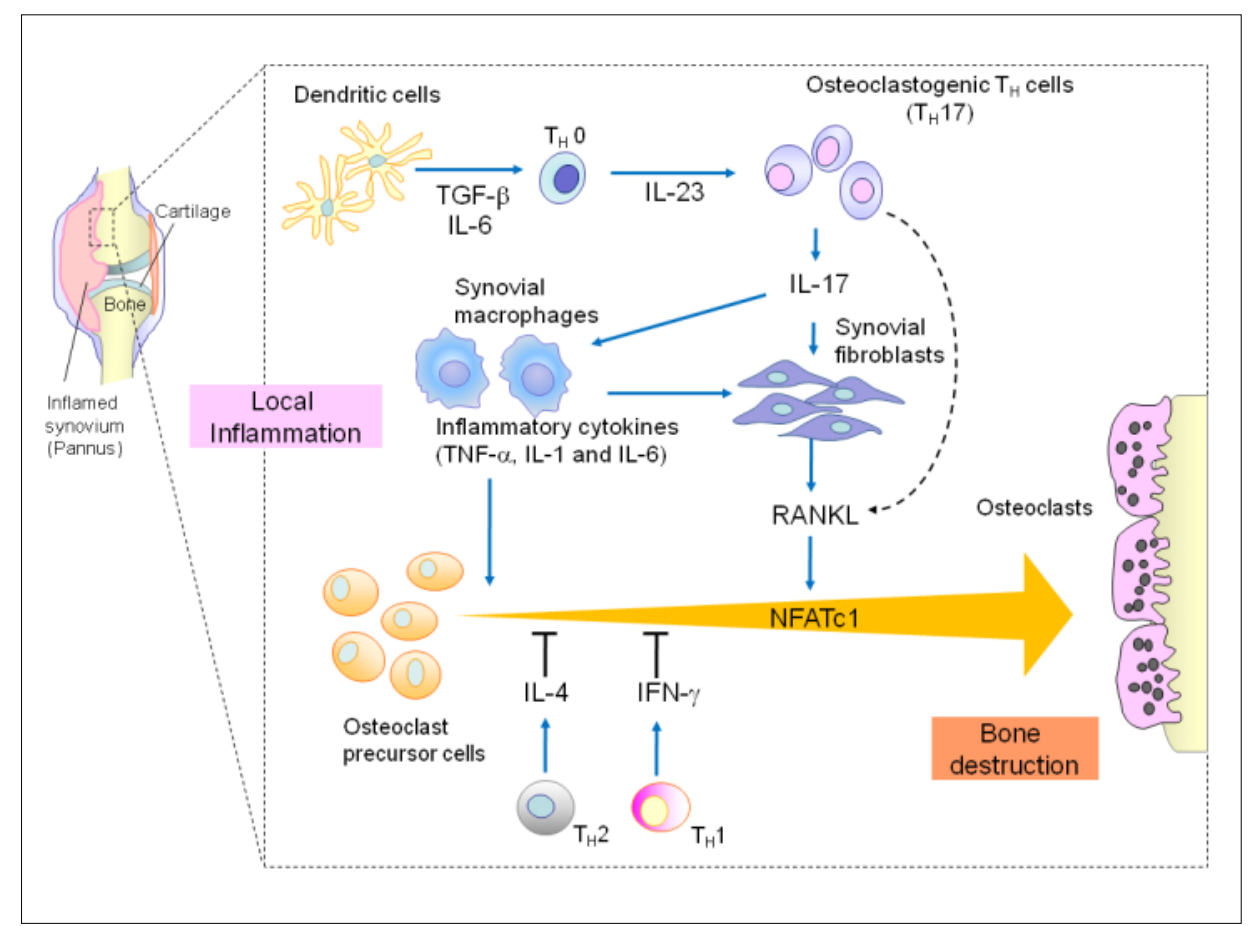

Fig.2 Mechanisms of bone destruction in arthritis

In rheumatoid arthritis, inflammatory synovium invades and destroys bone, an effect which is mediated by osteoclasts. The synovium includes synovial macrophages and fibroblasts in addition to the infiltrating CD4+ T-cells. Interleukin-17 (IL-17)-producing T helper cells (TH17 cells) are the only osteoclastogenic $\mathrm{TH}_{\mathrm{H}}$-cell subset ( $\mathrm{THOC}_{\mathrm{H}}$ cells) characterized thus far. $\mathrm{TH}_{\mathrm{H}} 7$ cells do not produce interferon- $\gamma$ (IFN- $\gamma$ ), which suppresses RANKL signaling, but do secrete relatively large amounts of IL-17, which induces RANKL on synovial fibroblasts. IL-17 also stimulates local inflammation and activates synovial macrophages to secrete proinflammatory cytokines such as TNF- $\alpha$, IL-1 and IL-6. These cytokines activate osteoclastogenesis by either directly acting on osteoclast precursor cells or inducing RANKL on synovial fibroblasts. TH17 cells also express RANKL on their membranes, which contribute to the enhanced osteoclastogenesis to a certain extent. The induction of TH17 cells is regulated by IL-6, TGF- $\beta$ and IL-23 produced by dendritic cells. TH1 and TH2 cells inhibit osteoclastogenesis through the production of IFN- $\gamma$ and IL-4, respectively.

\section{Conclusion}

The bone and immune systems share a remarkable array of molecules and regulatory mechanisms. Despite recent advances in the field of osteoimmunology, a number of questions persist. It remains unclear, for example, how distinct functions are affected through similar mechanisms. As the bone and the immune system are so demonstrably closely intermingled, all factors that regulate immune cells should be investigated for their effect on bone and vice versa. This approach will be facilitated by the increasing availability of genetically modified mice. Such animal models will surely lead to a deeper understanding of the molecular basis for the cell lineage specifications, and, perhaps most importantly, cell type-specific treatments, despite the similarity and indeed, overlap of the two systems. Therefore, there is reason to believe that both clinical and non-clinical researchers will productively benefit from the emerging insights obtained in the field of osteoimmunology.

\section{Acknowledgments}

This work was supported in part by a grant for ERATO, the Takayanagi Osteonetwork Project from the Japan Science and Technology Agency; Grant-in-Aids for Young Scientist A from the Japan Society for the Promotion of Science (JSPS); Grant-in-Aid for Challenging Exploratory Research from the JSPS; grants for Global Center of Excellence Program from the Ministry of Education, Culture, Sports, Science and Technology 
of Japan (MEXT); and grants from Tokyo Biochemical Research Foundation, Life Science foundation of Japan, Takeda Science Foundation, Uehara Memorial Foundation, Nakatomi Foundation, Nagao Memorial Foundation, Kowa Life Science Foundation, Naito Foundation, Ichiro Kanehara Foundation, Senri Life Science Foundation and Astellas Foundation for Research on Metabolic Disorders.

\section{References}

1) Takayanagi H: Osteoimmunology: shared mechanisms and crosstalk between the immune and bone systems. Nat Rev Immunol. 2007; 7: 292-304.

2) Walsh MC, Kim N, Kadono Y, Rho J, Lee SY, Lorenzo J, Choi Y: Osteoimmunology: interplay between the immune system and bone metabolism. Annu Rev Immunol. 2006; 24: 33-63.

3) Takahashi N, Akatsu T, Udagawa N, Sasaki T, Yamaguchi A, Moseley JM, Martin TJ, Suda T: Osteoblastic cells are involved in osteoclast formation. Endocrinology. 1988; 123: 2600-2602.

4) Suda T, Takahashi N, Udagawa N, Jimi E, Gillespie MT, Martin TJ: Modulation of osteoclast differentiation and function by the new members of the tumor necrosis factor receptor and ligand families. Endocr Rev. 1999; 20: 345-357.

5) Nakashima T, Takayanagi H: Osteoimmunology: crosstalk between the immune and bone systems. J Clin Immunol. 2009; 29: 555-567.

6) Nakashima T, Kobayashi Y, Yamasaki S, Kawakami A, Eguchi K, Sasaki H, Sakai H: Protein expression and functional difference of membrane-bound and soluble receptor activator of NF- $\kappa$ B ligand: modulation of the expression by osteotropic factors and cytokines. Biochem Biophys Res Commun. 2000; 275: 768-775.

7) Schlondorff J, Lum L, Blobel CP: Biochemical and pharmacological criteria define two shedding activities for TRANCE/OPGL that are distinct from the tumor necrosis factor alpha convertase. J Biol Chem. 2001; 276: 1466514674.

8) Miyamoto T, Arai F, Ohneda O, Takagi K, Anderson DM, Suda T: An adherent condition is required for formation of multinuclear osteoclasts in the presence of macrophage colony-stimulating factor and receptor activator of nuclear factor $\kappa$ B ligand. Blood. 2000; 96: 4335-4343.

9) Hikita A, Yana I, Wakeyama H, Nakamura M, Kadono Y, Oshima Y, Nakamura K, Seiki M, Tanaka S: Negative regulation of osteoclastogenesis by ectodomain shedding of receptor activator of NF- $\kappa$ B ligand. J Biol Chem. 2006; 281: 36846-36855.
10) Jones DH, Nakashima T, Sanchez OH, Kozieradzki I, Komarova SV, Sarosi I, Morony S, Rubin E, Sarao R, Hojilla CV, Komnenovic V, Kong YY, Schreiber M, Dixon SJ, Sims SM, Khokha R, Wada T, Penninger JM: Regulation of cancer cell migration and bone metastasis by RANKL. Nature. 2006; 440: 692-696.

11) Jimi E, Akiyama S, Tsurukai T, Okahashi N, Kobayashi K, Udagawa N, Nishihara T, Takahashi N, Suda T: Osteoclast differentiation factor acts as a multifunctional regulator in murine osteoclast differentiation and function. J Immunol. 1999; 163: 434-442.

12) Theill LE, Boyle WJ, Penninger JM: RANK-L and RANK: $\mathrm{T}$ cells, bone loss, and mammalian evolution. Annu Rev Immunol. 2002; 20: 795-823.

13) Nakashima T, Hayashi M, Fukunaga T, Kurata K, Oh-Hora M, Feng JQ, Bonewald LF, Kodama T, Wutz A, Wagner EF, Penninger JM, Takayanagi H: Evidence for osteocyte regulation of bone homeostasis through RANKL expression. Nat Med. 2011; 17: 1231-1234.

14) Lomaga MA, Yeh WC, Sarosi I, Duncan GS, Furlonger C, Ho A, Morony S, Capparelli C, Van G, Kaufman S, van der Heiden A, Itie A, Wakeham A, Khoo W, Sasaki T, Cao Z, Penninger JM, Paige CJ, Lacey DL, Dunstan CR, Boyle WJ, Goeddel DV, Mak TW: TRAF6 deficiency results in osteopetrosis and defective interleukin-1, CD40, and LPS signaling. Genes Dev. 1999; 13: 1015-1024.

15) Naito A, Azuma S, Tanaka S, Miyazaki T, Takaki S, Takatsu K, Nakao K, Nakamura K, Katsuki M, Yamamoto T, Inoue $\mathrm{J}$ : Severe osteopetrosis, defective interleukin-1 signalling and lymph node organogenesis in TRAF6-deficient mice. Genes Cells. 1999; 4: 353-362.

16) Wong BR, Besser D, Kim N, Arron JR, Vologodskaia M, Hanafusa H, Choi Y: TRANCE, a TNF family member, activates Akt/PKB through a signaling complex involving TRAF6 and c-Src. Mol Cell. 1999; 4: 1041-1049.

17) Kobayashi N, Kadono Y, Naito A, Matsumoto K, Yamamoto T, Tanaka S, Inoue J: Segregation of TRAF6-mediated signaling pathways clarifies its role in osteoclastogenesis. EMBO J. 2001; 20: 1271-1280.

18) Gohda J, Akiyama T, Koga T, Takayanagi H, Tanaka S, Inoue J: RANK-mediated amplification of TRAF6 signaling leads to NFATc1 induction during osteoclastogenesis. EMBO J. 2005; 24: 790-799.

19) Wada T, Nakashima T, Oliveira-dos-Santos AJ, Gasser J, Hara H, Schett G, Penninger JM: The molecular scaffold Gab2 is a crucial component of RANK signaling and 
osteoclastogenesis. Nat Med. 2005; 11: 394-399.

20) Bai S, Kitaura H, Zhao H, Chen J, Muller JM, Schule R, Darnay B, Novack DV, Ross FP, Teitelbaum SL: FHL2 inhibits the activated osteoclast in a TRAF6-dependent manner. J Clin Invest. 2005; 115: 2742-2751.

21) Shinohara M, Koga T, Okamoto K, Sakaguchi S, Arai K, Yasuda H, Takai T, Kodama T, Morio T, Geha RS, Kitamura D, Kurosaki T, Ellmeier W, Takayanagi H: Tyrosine kinases Btk and Tec regulate osteoclast differentiation by linking RANK and ITAM signals. Cell. 2008; 132: 794-806.

22) Franzoso G, Carlson L, Xing L, Poljak L, Shores EW, Brown KD, Leonardi A, Tran T, Boyce BF, Siebenlist U: Requirement for NF- $\kappa$ B in osteoclast and B-cell development. Genes Dev 1997; 11: 3482-3496.

23) Iotsova V, Caamano J, Loy J, Yang Y, Lewin A, Bravo R: Osteopetrosis in mice lacking NF- $\kappa \mathrm{B} 1$ and $\mathrm{NF}-\kappa \mathrm{B} 2$. Nat Med. 1997; 3: 1285-1289.

24) Wagner EF, Eferl R: Fos/AP-1 proteins in bone and the immune system. Immunol Rev. 2005; 208: 126-140.

25) Sato K, Suematsu A, Nakashima T, Takemoto-Kimura S, Aoki K, Morishita Y, Asahara H, Ohya K, Yamaguchi A, Takai T, Kodama T, Chatila TA, Bito H, Takayanagi H: Regulation of osteoclast differentiation and function by the CaMK-CREB pathway. Nat Med. 2006; 12: 1410-1416.

26) Takayanagi H, Kim S, Koga T, Nishina H, Isshiki M, Yoshida H, Saiura A, Isobe M, Yokochi T, Inoue J, Wagner EF, Mak TW, Kodama T, Taniguchi T: Induction and activation of the transcription factor NFATc1 (NFAT2) integrate RANKL signaling for terminal differentiation of osteoclasts. Dev Cell 2002; 3: 889-901.

27) Crabtree GR, Olson EN: NFAT signaling: choreographing the social lives of cells. Cell. 2002; 109 Suppl: S67-S79.

28) Hogan PG, Chen L, Nardone J, Rao A: Transcriptional regulation by calcium, calcineurin, and NFAT. Genes Dev. 2003; 17: 2205-2232.

29) Asagiri M, Sato K, Usami T, Ochi S, Nishina H, Yoshida H, Morita I, Wagner EF, Mak TW, Serfling E, Takayanagi $\mathrm{H}$ : Autoamplification of NFATc1 expression determines its essential role in bone homeostasis. J Exp Med. 2005; 202: 1261-1269.

30) Matsuo K, Galson DL, Zhao C, Peng L, Laplace C, Wang KZ, Bachler MA, Amano H, Aburatani H, Ishikawa H, Wagner EF: Nuclear factor of activated T-cells (NFAT) rescues osteoclastogenesis in precursors lacking c-Fos. J Biol Chem. 2004; 279: 26475-26480.

31) Zhao B, Takami M, Yamada A, Wang X, Koga T, Hu X,
Tamura T, Ozato K, Choi Y, Ivashkiv LB, Takayanagi H, Kamijo R: Interferon regulatory factor- 8 regulates bone metabolism by suppressing osteoclastogenesis. Nat Med. 2009; 15: 1066-1071.

32) Miyauchi Y, Ninomiya K, Miyamoto H, Sakamoto A, Iwasaki R, Hoshi H, Miyamoto K, Hao W, Yoshida S, Morioka H, Chiba K, Kato S, Tokuhisa T, Saitou M, Toyama Y, Suda T, Miyamoto T: The Blimp1-Bcl6 axis is critical to regulate osteoclast differentiation and bone homeostasis. $\mathrm{J}$ Exp Med, 2010; 207: 751-762.

33) Kim K, Kim JH, Lee J, Jin HM, Kook H, Kim KK, Lee SY, Kim N: MafB negatively regulates RANKL-mediated osteoclast differentiation. Blood. 2007; 109: 3253-3259.

34) Nishikawa K, Nakashima T, Hayashi M, Fukunaga T, Kato S, Kodama T, Takahashi S, Calame K, Takayanagi H: Blimp1-mediated repression of negative regulators is required for osteoclast differentiation. Proc Natl Acad Sci USA. 2010; 107: 3117-3122.

35) Koga T, Inui M, Inoue K, Kim S, Suematsu A, Kobayashi E, Iwata T, Ohnishi H, Matozaki T, Kodama T, Taniguchi T, Takayanagi H, Takai T: Costimulatory signals mediated by the ITAM motif cooperate with RANKL for bone homeostasis. Nature. 2004; 428: 758-763.

36) Bromley M, Woolley DE: Chondroclasts and osteoclasts at subchondral sites of erosion in the rheumatoid joint. Arthritis Rheum. 1984; 27: 968-975.

37) Takayanagi H, Oda H, Yamamoto S, Kawaguchi H, Tanaka S, Nishikawa T, Koshihara Y: A new mechanism of bone destruction in rheumatoid arthritis: synovial fibroblasts induce osteoclastogenesis. Biochem Biophys Res Commun. 1997; 240: 279-286.

38) Gravallese EM, Harada Y, Wang JT, Gorn AH, Thornhill TS, Goldring SR: Identification of cell types responsible for bone resorption in rheumatoid arthritis and juvenile rheumatoid arthritis. Am J Pathol. 1998; 152: 943-951.

39) Gravallese EM, Manning C, Tsay A, Naito A, Pan C, Amento E, Goldring SR: Synovial tissue in rheumatoid arthritis is a source of osteoclast differentiation factor. Arthritis Rheum. 2000; 43: 250-258.

40) Takayanagi H, Iizuka H, Juji T, Nakagawa T, Yamamoto A, Miyazaki T, Koshihara Y, Oda H, Nakamura K, Tanaka $\mathrm{S}$ : Involvement of receptor activator of nuclear factor $\kappa \mathrm{B}$ ligand/osteoclast differentiation factor in osteoclastogenesis from synoviocytes in rheumatoid arthritis. Arthritis Rheum. 2000; 43: 259-269.

41) Pettit AR, Ji H, von Stechow D, Muller R, Goldring SR, 
Choi Y, Benoist C, Gravallese EM: TRANCE/RANKL knockout mice are protected from bone erosion in a serum transfer model of arthritis. Am J Pathol. 2001; 159: 16891699.

42) Redlich K, Hayer S, Ricci R, David JP, Tohidast-Akrad M, Kollias G, Steiner G, Smolen JS, Wagner EF, Schett G: Osteoclasts are essential for TNF- $\alpha$-mediated joint destruction. J Clin Invest. 2002; 110: 1419-1427.

43) Kong YY, Feige U, Sarosi I, Bolon B, Tafuri A, Morony S, Capparelli C, Li J, Elliott R, McCabe S, Wong T, Campagnuolo G, Moran E, Bogoch ER, Van G, Nguyen LT, Ohashi PS, Lacey DL, Fish E, Boyle WJ, Penninger JM: Activated T cells regulate bone loss and joint destruction in adjuvant arthritis through osteoprotegerin ligand. Nature. 1999; 402: 304-309.

44) Takayanagi H, Juji T, Miyazaki T, Iizuka H, Takahashi T, Isshiki M, Okada M, Tanaka Y, Koshihara Y, Oda H, Kurokawa T, Nakamura K, Tanaka S: Suppression of arthritic bone destruction by adenovirus-mediated csk gene transfer to synoviocytes and osteoclasts. J Clin Invest. 1999; 104: 137-146.

45) Lubberts E, Joosten LA, Chabaud M, van Den Bersselaar L, Oppers B, Coenen-De Roo CJ, Richards CD, Miossec P, van Den Berg WB: IL-4 gene therapy for collagen arthritis suppresses synovial IL-17 and osteoprotegerin ligand and prevents bone erosion. J Clin Invest. 2000; 105: 1697-1710.

46) Horwood NJ, Kartsogiannis V, Quinn JM, Romas E, Martin TJ, Gillespie MT: Activated T lymphocytes support osteoclast formation in vitro. Biochem Biophys Res Commun. 1999; 265: 144-150.

47) Takayanagi H, Ogasawara K, Hida S, Chiba T, Murata S, Sato K, Akinori T, Yokochi T, Oda H, Tanaka K, Nakamura $\mathrm{K}$, Taniguchi T: T cell-mediated regulation of osteoclastogenesis by signalling cross-talk between RANKL and
IFN- $\gamma$. Nature. 2000; 408: 600-605.

48) Sato K, Suematsu A, Okamoto K, Yamaguchi A, Morishita Y, Kadono Y, Tanaka S, Kodama T, Akira S, Iwakura Y, Cua DJ, Takayanagi H: Th17 functions as an osteoclastogenic helper $\mathrm{T}$ cell subset that links $\mathrm{T}$ cell activation and bone destruction. J Exp Med. 2006; 203: 2673-2682.

49) Kotake S, Udagawa N, Takahashi N, Matsuzaki K, Itoh K, Ishiyama S, Saito S, Inoue K, Kamatani N, Gillespie MT, Martin TJ, Suda T: IL-17 in synovial fluids from patients with rheumatoid arthritis is a potent stimulator of osteoclastogenesis. J Clin Invest. 1999; 109: 1345-1352.

50) Bailey SL, Schreiner B, McMahon EJ, Miller SD: CNS myeloid DCs presenting endogenous myelin peptides 'preferentially' polarize CD4+ ${ }^{+} \mathrm{H} 17$ cells in relapsing EAE. Nat Immunol. 2007; 8: 172-180.

51) Ousman SS, Tomooka BH, van Noort JM, Wawrousek EF, O'Conner K, Hafler DA, Sobel RA, Robinson WH, Steinman $\mathrm{L}$ : Protective and therapeutic role for $\alpha \mathrm{B}$-crystallin in autoimmune demyelination. Nature. 2007; 448: 474-479.

52) van Beelen AJ, Zelinkova Z, Taanman-Kueter EW, Muller FJ, Hommes DW, Zaat SA, Kapsenberg ML, de Jong EC: Stimulation of the intracellular bacterial sensor NOD2 programs dendritic cells to promote interleukin-17 production in human memory T cells. Immunity. 2007; 27: 660-669.

53) Weaver CT, Harrington LE, Mangan PR, Gavrieli M, Murphy KM: Th17: an effector CD4 T cell lineage with regulatory T cell ties. Immunity. 2006; 24: 677-688.

54) Iwakura Y, Ishigame H: The IL-23/IL-17 axis in inflammation. J Clin Invest. 2006; 116: 1218-1222.

55) Okamoto K, Iwai Y, Oh-Hora M, Yamamoto M, Morio T, Aoki K, Ohya K, Jetten AM, Akira S, Muta T, Takayanagi $\mathrm{H}: \mathrm{I} \kappa \mathrm{B} \zeta$ regulates $\mathrm{T} H 17$ development by cooperating with ROR nuclear receptors. Nature. 2010; 464: 1381-1385. 